\title{
A Herança em comum na BNCC
}

\author{
Bruno Fernando dos Santos Castro ${ }^{1}$ \\ Marinazia Cordeiro Pinto ${ }^{2}$ \\ Virginia Maria Barcellos ${ }^{3}$ \\ Wenderson Silva Oliveira ${ }^{4}$
}

\begin{abstract}
RESUMO
O artigo em questão busca interpelar o texto da BNCC com as inquietações dos autores. Utilizando-nos de autores do campo pós-estrutural, os objetivos do trabalho são 1) Pensar se, dentro do universo da BNCC, há a possibilidade da ideia de competência estar ligada à ideia de performatividade (BROWN, 2015; BUTLER, 2018); 2) Também, dentro dos processos identitários e deixando-nos guiar pelas narrativas do documento em questão, pensar se existe uma herança comum a todos nós que justifique um único documento de base; 3) Como essa herança performada no texto da BNCC produz sentidos de aprendizagem que operam discursivamente uma certa racionalidade neoliberal economicizante e competitiva (BROWN, 2015)? Navegando assim, nos questionamos em que consistiria uma padronização curricular. Para além disso, questionamos se seria possível pensarmos o que é essencial para ser aprendido por todas as pessoas que estão nas escolas. O texto começa contextualizando o terreno a ser explorado e lançando as perguntas-chave. A seguir, aprofundamos as interpretações possíveis da BNCC, friccionando-as com perspectivas de autores como Derrida, Macedo e Biesta. Ao final, afirmamos com certo conforto que a tentativa de combinação de ideias como educação e aprendizagem proposta no texto da BNCC, além de não se sustentar, age como polos positivos e se repelem, por esta última não dar conta da performatividade constitutiva da educação.
\end{abstract}

PALAVRAS-CHAVE: BNCC. herança. currículo.

\begin{abstract}
This article seeks to question the text of the BNCC with the concerns of the authors. Using authors from the poststructural field, the objectives of the work are 1) To think about whether, within the universe of the BNCC, there is the possibility of the idea of competence being linked to the idea of performativity (BROWN, 2015; BUTLER, 2018); 2) Also, within the identity processes and letting us be guided by the narratives of the document in question, to think about whether there is a common heritage in all of us that justifies a single base document; 3) How does this heritage performed in the BNCC text produces meanings of learning that discursively operate a certain economic and competitive neoliberal rationality (BROWN, 2015)? This way, we asked ourselves what a curricular standardization would consist of. Furthermore, we asked ourselves if it would be possible to think about what is essential to be learned by everyone in schools. The text begins by contextualizing the terrain to be explored and asking key questions. Next, we deepen the possible interpretations of the BNCC, comparing them to the perspectives of authors such as Derrida, Macedo and Biesta. In the end, we affirm with some comfort that the attempt to combine ideas such as education and learning proposed in the BNCC text, in addition to not working, acts as positive poles that repel each other, as the latter does not account for the constitutive performativity of education.
\end{abstract}

Keywords: BNCC. heritage. curriculum.

\footnotetext{
${ }^{1}$ Doutorando do ProPEd UERJ. Bolsista da FAPERJ.

2 Doutoranda do ProPEd UERJ. Bolsista da FAPERJ.

${ }^{3}$ Doutoranda do ProPEd UERJ. Bolsista da CAPES

${ }^{4}$ Doutorando do Programa de Pós-graduação da Universidade Estadual do Ceará.
} 


\section{Introdução}

Os debates acerca de uma possível centralização dos currículos não são novos. A Constituição Federal de 1988 já acenava para a possibilidade dessa centralização, do mesmo modo que os dispositivos legais educacionais que a sucedem. De certo modo, os Parâmetros Curriculares Nacionais (PCN) apresentam essa tentativa, apesar de não terem uma força de lei que obrigasse os sistemas educacionais a se organizarem a partir dele. Nesse aspecto, a Base Nacional Comum Curricular (BNCC) é um efeito dessas demandas por padronização, acompanhadas pela sombra das avaliações externas e a busca de melhores resultados para a educação nacional, sobretudo a educação pública. Dessa perspectiva, surgem as seguintes perguntas: afinal, em que consistiria essa padronização curricular? Seria possível pensarmos o que é essencial para ser aprendido por todas as pessoas que estão nas escolas?

Nas leituras do texto da BNCC (2018), podemos identificar que sua maior característica é definir um conjunto de aprendizagens essenciais a serem desenvolvidas na Educação Básica, justificativa esta que sustenta a argumentação de sua existência e resistência. $O$ documento encontra terreno fértil nos preceitos do Plano Nacional de Educação (PNE 2014-2024), bem como na Lei ${ }^{\circ}$ 9.394/1996, que justificam sua necessidade de ser referenciada em todos os sistemas e redes de ensino. Logo, esse projeto de unificação curricular, iniciado com maior força no ano de 2015, aglutina interesses políticos difusos, com participação da União Nacional dos Dirigentes Municipais de Educação (UNDIME) e do Conselho Nacional de Secretários de Educação, da Conferência Nacional dos Trabalhadores em Educação (CNTE) e intensificandose pelo Movimento pela Base Nacional Comum da Educação, criado em 2013 e formado por institutos de iniciativa privada. Frente a isso, não nos esqueçamos dos intensos movimentos de rua iniciados em junho de 2013, que também abriram campo para uma frente conservadora e neoliberal, que se autodesignava apartidária e antipartidária, cuja bandeira principal era a retirada do Partido dos Trabalhadores (PT) da Presidência da República.

Esses movimentos impactam, diretamente, as políticas e práticas do PNE 2014-2024 e as discussões iniciais em torno da composição da BNCC. Faz-se necessário lembrar, do mesmo modo, que houve várias reuniões do Movimento Brasil Livre (MBL) que contaram com a presença do movimento Escola Sem Partido (ESP), nas quais determinadas pautas giravam em torno dos planos educacionais em todos os níveis e dos currículos escolares. Esses movimentos foram pivotantes da pressão política para a retirada do partido petista do poder presidencial; e, com isso, um novo mapa político-educacional foi desenhado após o impedimento da então Presidente Dilma Rousseff. 
A primeira versão do documento foi disponibilizada para consulta pública no ano de 2015, com elaboração do Ministério da Educação (MEC), com o apoio da UNDIME e do CONSED. Essa versão parte do emprego dos objetivos de aprendizagem, que se tratam de conhecimentos considerados fundamentais a que os estudantes devem ter acesso para que sejam garantidos tanto o direito de aprendizagem quanto de desenvolvimento. Contudo, não há uma justificativa no documento para essa escolha por objetivos de aprendizagem, tampouco há as concepções curriculares em que a Base se apoia.

A segunda versão do documento, que é publicada no ano de 2016, após seis meses de debate e reelaboração, traz consigo mudanças profundas em relação à proposta inicial. Há a inserção das discussões sobre as relações étnico-raciais, questões de gênero, educação inclusiva, dentre outras. Há, do mesmo modo, uma definição mais precisa em relação aos princípios pedagógicos e as peculiaridades de cada modalidade da Educação Básica, trazendo consigo aspectos éticos, políticos e estéticos.

A terceira e última versão, pós-retirada de Dilma Rousseff do poder presidencial, publicada em 2017 é bastante diferente da versão anterior. Nessa versão, inicia a noção das aprendizagens essenciais, ou seja, aquilo que estudantes devem saber no período escolar, atrelada a uma justificativa da aprendizagem por competências, desenhada pelas avaliações internacionais, sobretudo de países neoliberais. A competência, na BNCC, virá como uma mobilização dos conhecimentos e das habilidades para resolver as demandas da vida cotidiana; preparando para o exercício, segundo o texto, da cidadania e o preparo, do mesmo modo, para o mercado de trabalho. Assim, o currículo, nessa perspectiva, adquire uma forte inspiração salvacionista, na qual conseguirá fazer com que alunas e alunos sejam capazes de ter habilidades de lidar com problemas para que sejam mais produtivos, flertando com uma visão mercadológica de educação, fazendo com que essas aprendizagens essenciais acompanhem uma ótica neoliberalista; por isso, a participação efetiva de institutos e associações de caráter privado nessa última versão do texto e no fomento para a publicação e implementação.

Com base nesse relato, podemos sugerir que existe uma ideia de salvação imbricada na BNCC, ideia essa que tenciona outros documentos como, por exemplo, os PCN. Como dito antes, essa ideia não é uma novidade entre as estratégias coloniais de dominação. Uma teia que projeta a emancipação e justifica o controle. Uma herança aliada a uma ótica neoliberal, e uma base que está de alguma maneira consagrando uma herança.

Os objetivos do presente artigo são 1) Pensar se, dentro do universo da BNCC, há a possibilidade da ideia de competência estar ligada à ideia de performatividade (BROWN, 2015; BUTLER, 2018); 2) Também, dentro dos processos identitários e deixando-nos guiar pelas 
narrativas do documento em questão, pensar se existe uma herança comum a todos nós que justifique um único documento de base; 3) Pensar como essa herança performada no texto da BNCC produz sentidos de aprendizagem que operam discursivamente uma certa racionalidade neoliberal economicizante e competitiva (BROWN, 2015)?

Será que a educação é passível de controle e previsibilidade, será que tem o potencial de restaurar e conciliar a vida de uma pessoa e de um país? Como se existisse uma relação direta e inquestionável entre o acesso ao conhecimento pela educação formal e a solução dos problemas de um país. Nesse contexto, a BNCC seria uma ferramenta poderosa de transformação e fortalecimento da democracia, promovendo acesso ao conhecimento de forma, milagrosamente, igualitária para todo o país.

Porém na prática isso não se constata. Então, quais seriam os entraves para tão auspicioso documento? Independentemente de qualquer ideologia político-partidária em primeiro lugar, a proposta de um documento que unificaria a educação no território nacional é uma proposta inexequível, muito antes do que a aplicabilidade do que se propõe; trata-se de uma impossibilidade já na leitura do texto do documento. Isso se dá porque ler também constitui construir sentidos para os textos. Pode-se, então, considerar que a leitura é também uma enunciação. Mesmo que esse documento atendesse apenas a uma escola, a cada sala em que fosse lido, a cada momento, por cada pessoa e até pela mesma pessoa em momentos diferentes, novos sentidos seriam percebidos no texto. É o que Derrida (2009) denomina tradução. Um processo que não se aplica, para o filósofo, apenas à transposição de um texto de uma língua para outra e sim a todo processo de recepção - não apenas pela leitura - de textos. O sentido nunca se fecha, ele é sempre suplementado pelos leitores. Além dessa primeira impossibilidade, tem-se a imprevisibilidade da educação que, segundo Elizabeth Macedo (2019), é acontecimento porque, como já dissemos, diz respeito a algo que não se submete ao cálculo, algo que não se pode prever, algo que desestrutura o estabelecido. Educação não é produção industrial em que a matéria prima entra no circuito de um jeito e, de forma programada, sai na outra ponta como um produto previsto e conforme o que se tinha planejado. Não se pode manipular o desenvolvimento do aluno, pode-se planejar e ter objetivos sim; mas esses serão vivenciados de forma diferente em cada turma e por cada aluno. Nas palavras de Elizabeth Macedo (2019), 
$\mathrm{Na}$ topologia invaginada, não linear, em que o por-vir ganha sentido, o fracasso da escola em formar para o futuro imaginado é, talvez, a única certeza, não porque a utopia não pode ser atingida, mas porque a educação como um princípio regulador só pode se fazer sob seus próprios escombros. A educação, ao contrário, é acontecimento, tem a ver com os eventos imprevistos que "rompem absolutamente com a normalidade constituída". Ela só acontece acolhendo o "monstro que chega".

Um terceiro impedimento para a implantação da base seria o fato de que, em seu texto, o conhecimento é apresentado como algo pronto que deve ser acessado pelos alunos brasileiros. Ou seja, há no documento uma objetificação do conhecimento, além da objetificação dos alunos e dos professores. O conhecimento seria um conhecimento para (MACEDO, 2016), um bem economizado, sob efeito de proprietarização, a ser adquirido para se desenvolver de forma digna na sociedade, como se ele desse aos alunos poder de troca e fizesse dos alunos, eles mesmos, uma espécie de capital, um capital humano nos termos de Brown (2015).

Esses impedimentos, em algum sentido, nos remetem à noção de herança tal qual nos traz Derrida (2004). Segundo esse filósofo, trata-se de uma herança que diz respeito à crença em verdades instituídas. Algo de que temos dificuldade de escapar, que é quase uma necessidade. A norma vigente opera no sentido de nos fazer acreditar que existem verdades e que essas verdades são conhecidas por alguns que podem e devem dividi-las com o outro que está na escuridão. É esse o tom dos documentos oficiais que orquestram a educação em nosso país. Falamos de herança porque essa relação de alguém que sabe mais e vai ao encontro de quem sabe menos, ou não sabe nada, para mostrar um caminho, para resgatá-lo da falta de conhecimento, remonta a uma herança colonial, remonta ao encontro entre o homem civilizado europeu e o homem bárbaro, o selvagem dos demais continentes.

\section{Para além da aprendizagem?}

Considerando essas impossibilidades acima descritas, de que a base alcance o objetivo pelo qual diz-se que ela foi construída; a saber, promover as aprendizagens essenciais para todos os alunos do país; queremos partir de Biesta (2017) para pensar a linguagem da aprendizagem na educação. Ele afirma que coloca suas questões radicalmente em aberto, porque não apresenta uma resposta prévia, mas busca superar os fundamentos da educação moderna para seguir operando discursivamente com o significante aprendizagem. Dessa maneira, "Para além da aprendizagem" seria a superação de certas formas de aprendizagem, como a aprendizagem moderna para emancipação e a aprendizagem contemporânea economicizada. Segundo o autor, a tarefa que estaria diante de nós seria a de reinventar uma linguagem para a educação na qual a aprendizagem assume novos sentidos, mas segue-se operando com esse significante. Nesse 
sentido, assumindo que uma linguagem foi e já está inventada, resta a ação voluntariosa de inventar novamente uma linguagem para a educação, mas seguir operando com a ideia de aprendizagem.

Essa linguagem a ser superada pode ser lida em textos que buscam redefinir sentidos de ensinar como apoiar ou facilitar a aprendizagem, propiciar oportunidades ou experiências de aprendizagem, na qual os estudantes são vistos como aprendentes e o "ensino como apoio e facilitação para a aprendizagem" (BIESTA, 2017, posição 318) (Cf.: BRASIL, 2018, p. 8). Biesta (2017) localiza a mudança de linguagem para essa nova aprendizagem durante o processo de desmonte do estado de bem-estar social e difusão do neoliberalismo no Atlântico Norte. Marcadamente mais individualista em sua forma e conteúdo e em seus objetivos, pode ser considerado como um dos sentidos da consolidação do homo economicus em detrimento do homo politicus, como elaborado por Brown (2015).

Biesta diz que essa nova linguagem da educação trata a educação a partir de termos de uma transação econômica, apoiado em três ideias: (1) um consumidor-aprendente que supostamente sabe o que deseja demanda que (2) o provedor (educação, escola, professor) satisfaça sua necessidade predefinida, tratando a (3) educação como a mercadoria negociada nessa relação. Essa ideia sugere uma estrutura em que "as únicas questões que podem ser significativamente propostas são questões técnicas, isto é, questões sobre a eficiência e a eficácia do processo educacional” (BIESTA, 2017, posição 418, grifos do autor), e sai em defesa de que "as questões sobre os conteúdos e o objetivo da aprendizagem devem ser vistas em primeiro lugar como questões educacionais importantes" (idem, ibidem). Portanto, identifica que o problema da nova linguagem da aprendizagem é facilitar uma compreensão econômica da educação, o que tornaria mais difícil propor questões sobre o conteúdo e o objetivo para a educação.

Apesar de buscar manter estas questões sempre abertas, trabalha com a ideia de que a educação precisa ter um objetivo e um conteúdo, daí a superação, o "para além”, sem o abandono da ideia de aprendizagem, logo de ensino, método e avaliação. Quando tenta responder à pergunta de onde vem a educação, essa ideia é reafirmada ao dizer que "talvez comece com um aprendente que deseja aprender algo, que procura conhecimento (BIESTA, 2017, posição 451, grifos nossos). Ou seja, existe algo, um conhecimento, que o aprendente deseja, que o aprendente busca. Esse é um dos riscos de se operar a partir da ideia de conhecimento. Supor que o estudante possui uma potência desejante de conhecimento, por mais genérico que possa ser, já é criar uma ideia de sujeito que o precede. Se o que chamamos de sujeito só acontece na correspondência, a única maneira de não atentar contra a singularidade 
de qualquer alteridade é dizer sim, é acolhê-la em sua apresentação performativa, ao que respondo e me constituo nessa relação.

Mesmo pontuando que as questões apontadas são sempre abertas, durante o texto existe a ideia de um sujeito que tem desejo de um conteúdo, pois "educação só começa quando o aprendente está disposto a correr um risco" (BIESTA, 2017, posição 462). Nessa nova linguagem reinventada, a aprendizagem é trabalhada como resposta ao que é outro e diferente, que nos desafia, como condição de vir ao mundo, mostrando quem é você e em que posição está. Porém, "vir ao mundo não consiste definitivamente em autoexpressão" (idem, posição 506) e "não é qualquer resposta que bastará e deve ser simplesmente aceita", pois existe um sujeito que tem desejo, que decide aceitar as respostas, de maneira que "entrar no tecido social" é a consequência de respostas válidas, validadas na interação (idem, ibidem). Derrida (2004, p. 13) chama a atenção que devemos sempre partir da contradição formal e aparente entre a passividade da recepção e a decisão de dizer "sim", não existe decisão porque não existe uma consciência que decide. Nas palavras do autor,

\footnotetext{
Seria preciso portanto partir dessa contradição formal e aparente entre a passividade da recepção e a decisão de dizer "sim", depois selecionar, filtrar, interpretar, portanto transformar, não deixar intacto, incólume, não deixar salvo aquilo mesmo que se diz respeitar antes de tudo. E depois de tudo. Não deixar a salvo: salvar, talvez, ainda, por algum tempo, mas sem ilusão quanto a uma salvação final.
}

Ao buscar reinventar a linguagem da educação para uma outra aprendizagem, Biesta (2017) define a aprendizagem como vir ao mundo como ação de responder ao outro e assim ser também responsável pelo que é outro e por quem é outro. Nesse sentido, tarefa crucial da educação para esse fim seria criar oportunidades "desafiando os estudantes a responder confrontando com o que é outro e quem é outro" (idem, posição 530) - o que consistiria em localizar esse outro e representá-lo - assumindo que a responsabilidade primeira do educador é pela subjetividade do estudante, pelo que permite ser um ser singular e único e reconhecer a condição para sua vinda ao mundo nessa forma. Derrida (2014, p. 14) afirma que "é-se responsável perante aquilo que vem antes de si mas também perante o que está por vir, e portanto também perante a si mesmo" (grifos do autor). Porém, podemos interpretar que esse si mesmo já está dado em Biesta (2017) quando afirma que há um aprendente que deseja aprender algo e a educação como o que desafia a responder ao que é outro, mostrando quem é você e em que posição está (idem, posição 451-462).

A defesa de uma nova linguagem para educação em Biesta (2017), na intenção de ir além da aprendizagem, se torna a defesa de uma nova linguagem para a aprendizagem, para a 
"nova aprendizagem" que se consolidou pela racionalização da vida pela economia como um dos efeitos do neoliberalismo. Nessa dimensão, a economicização da educação é criticada por sua caracterização nas relações econômicas de troca, na qual a linguagem do consumidor, do fornecedor e da mercadoria associada às questões educacionais prevalece. A educação tomada como mercadoria é criticada enquanto inserida nessa linguagem econômica de mercado, mas a linguagem da educação como coisa permanece, na medida em que afirma que há um aprendente que deseja um conhecimento. É compreensível, contextualmente, a assertividade do autor ao escrever um livro que pretende reinventar uma linguagem para a educação e para a aprendizagem.

Buscaremos articular a dimensão pouco explorada por Biesta (2017) da educação como mercadoria, como coisa, a partir da ideia de Brown (2015) do neoliberalismo como economicização da vida, como "razão normativa que tomou forma como uma racionalidade governamental, estendendo uma formulação específica de valores, práticas e métricas econômicas para todas as dimensões da vida humana" (idem, p. 30). Não é a mera mercantilização de todas as esferas de atuação humana, a racionalidade neoliberal dissemina o modelo de mercado e configura exaustivamente os seres humanos como market actors em uma sociedade de mercado marcada pelo capital financeiro. Nessas condições, o ser humano é tomado como capital humano, para si e para o mercado, incentivando a busca pelo fortalecimento de seu posicionamento, de sua competitividade, de seu valor na sociedade (de mercado), investindo num empreendedorismo de si para inserir-se no networking e atrair investidores. Dessa maneira, a derrota da democracia liberal com a disseminação do neoliberalismo teria representado também a derrota do homo politicus, em favor do homo oeconomicus, com enormes consequências para as instituições democráticas, culturas e imaginários (idem, p. 31).

Brown (2015) comenta que a política neoliberal foi recorrentemente imposta através de decretos políticos e da força nos anos 1970-80, mas a neoliberalização posterior tem sido mais proclamada através de técnicas específicas de governança, desenhando e vendendo consenso a partir de soft powers. Nessa acepção, em que todas as dimensões da vida são economicizadas e todos nós somos atores nesse mercado, a troca, característica da concepção liberal de economia, dá lugar à competição como princípio básico do mercado. Essa mudança sutil, mais normativa do que natural, por demandar facilitações e suportes legais, significa que todos os atores nesse mercado são caracterizados como pequenos capitais (como capitais humanos, mais do que proprietários, trabalhadores ou consumidores) em meio ao capitalismo financeiro em que a competição assume uma importância maior do que a troca, e o empreendedorismo de si, o 
preparar-se para atrair investimento sempre ocorre em detrimento de outro. Dessa maneira, pessoas e práticas são economicizadas de maneiras que excedem a ideia de produção de riqueza; tornando normal, e mesmo normativa, a desigualdade por meio da legislação, da jurisprudência e do imaginário popular; criando uma democracia composta por vencedores, que se destacam por seu capital humano, e perdedores (idem, p. 38).

O processo de objetificação não é característico da economia de mercado financeiro em que vivemos, nem mesmo do capitalismo como um todo, apesar de ter sido tema recorrente no pensamento marxista, ao pensar sobre o processo de reificação que transforma ideias e seres humanos em mercadorias e de fetichização da mercadoria na qual as relações sociais são expressas na forma de relações de troca. Poderíamos afirmar que a objetificação faz parte de todo processo significativo no qual o significado seria o efeito de objetificação da diferença sequencial e contextual de significantes. Se não há significado, apenas efeito de significação, toda positividade de um significado é efeito de operações discursivas em torno de certas disseminações de significação. Seguindo esse caminho, todo significado é a objetificação de um sentido produzido na iterabilidade da performatividade (DERRIDA, 1991; BUTLER, 2018). Relacionando com a nossa leitura das ideias de Brown (2015), a positividade atribuída a efeitos de significação em nossa sociedade opera a partir de uma racionalidade neoliberal, caracterizada não apenas pela mercantilização de todas as esferas de atuação humana, mas principalmente pela disseminação do modelo discursivo de mercado. Neste modelo, efeitos de significação são objetificados como capital a ser investido e como garantia de retorno, numa relação em que a ideia de troca, fundamental para a economia liberal, é suplementada pela ideia de competitividade característica da economia de mercado financeiro especulativo em que vivemos.

Quando tudo é capital, formas coletivas de significação perdem força. Nesse movimento, é possível compreender o enfraquecimento de conquistas fundamentais da cidadania contemporânea, como direitos trabalhistas, seguridade social, e, principalmente, a diluição da importância dada à coisa pública e ao bem comum. Uma vez que passam a ser questionados, deixam de ser um fundamento, e são suplementados por fundamentos economicizantes. A economia como troca, como negociação e jogo, opera com o cálculo; porém, como as coisas trocadas são efeitos de objetificação, efeitos de significação, a dimensão do incalculável, da indecidibilidade, é constitutiva de toda interação.

Operar sob a lógica da economia, da troca, não requer a positividade da objetificação, essa positividade é invenção, quando passa a ser um objetivo, uma expectativa a ser alcançada, uma origem a ser revelada. É nessa diferenciação que podemos interpretar a ideia de 
economicização da vida relacionada à racionalidade neoliberal competitiva em Brown (2015, p. 36) e pensar também sobre todo pensamento educacional que opere a partir de significantes como aprendizagem e ensino (sua outra metade), que buscam eliminar o incalculável de toda troca. Não é possível dar conta da indecidibilidade constitutiva de todo processo de significação, reinventando sentidos ou amalgamando significantes. Mas é justamente por não ser possível que investimos radicalmente nessa possibilidade. Porém, é apenas o que fazemos e podemos fazer: investir sem garantias em possibilidades. Segundo Alice Lopes (2015, p. 123),

\begin{abstract}
Este investimento não é apenas teórico. Envolve tempo, trabalho, paixão, compromisso, ação. Está associado à produção política de uma comunidade normativa como efeito das articulações, inclusive teóricas, entre demandas diferenciais que estabilizam provisoriamente uma dada significação de norma. O investimento radical implica negociação, não necessariamente pacífica, entre diferentes representações particulares que podem ser universalizadas provisória e precariamente.
\end{abstract}

Assim, tentando, de alguma maneira, responder à educação evitando ideias que operem a partir de efeitos de presença, pensamos a educação em função do estudante e o estudar como significante a ser articulado para pensar sobre a performatividade da educação em contextos escolares.

\title{
Performatividade neoliberal, aprendizagem e a BNCC
}

Como lemos no trecho abaixo, a BNCC é apresentada enquanto documento normativo:

\begin{abstract}
A Base Nacional Comum Curricular (BNCC) é um documento de caráter normativo que define o conjunto orgânico e progressivo de aprendizagens essenciais que todos os alunos devem desenvolver ao longo das etapas e modalidades da Educação Básica. Este documento normativo aplica-se exclusivamente à educação escolar, tal como a define o $\S 1^{\circ}$ do Artigo $1^{\circ}$ da Lei de Diretrizes e Bases da Educação Nacional (LDB, Lei $n^{\circ} 9.394 / 1996$ ), e está orientado pelos princípios éticos, políticos e estéticos que visam à formação humana integral e à construção de uma sociedade justa, democrática e inclusiva, como fundamentado nas Diretrizes Curriculares Nacionais da Educação Básica (DCN) (BRASIL, 2017, p. 7)
\end{abstract}

Um documento que pretende definir aprendizagens essenciais para o desenvolvimento de competências, definidas como "mobilização de conhecimentos, práticas cognitivas e sócioemocionais, atitudes para resolver demandas complexas da vida cotidiana, do pleno exercício da cidadania e do mundo do trabalho" (BRASIL, 2018, p.8) (grifos nossos). Operar com a ideia de aprendizagem, e com a inescapável ideia de ensino, segue a lógica de troca de efeitos de objetificação, na qual os conteúdos, os conhecimentos, as competências são o objeto a ser apre(e)ndido, ou ensinado a ser aprendido para garantir a aprendizagem 
Seguindo com nosso entendimento, percebemos que a linguagem da educação na BNCC não ficou de fora dessa economicização de tudo produzida pelo neoliberalismo. A BNCC encarna nas suas propostas, direta ou indiretamente, os significantes e ideias mais caras ao neoliberalismo. Ela trabalha, na sua prática de medir a eficiência de suas ações, a questão da meritocracia quando propõe uma rotina de avaliações internas e externas com o objetivo de classificar, por meio de uma quantificação de acertos, as unidades federativas, os municípios, as escolas e os alunos. Traz também para seu bojo a ideia de que os estudantes, de forma individualizada, vão construir seu percurso formativo em um claro desmerecimento da coletividade, incentivando um "empreendedorismo de si mesmo". O aluno precisa investir no seu aprendizado para ter capital humano e sucesso profissional, estando disposto a ter resiliência e se adaptar às vontades do mercado e assumir para si uma espécie de culpa caso não consiga se adequar às circunstâncias do mundo do trabalho. Uma vez que o projeto foi definido e o caminho aprendido, bastaria a execução calculada do planejamento. Com um destino definido, seja a formação para o mercado de trabalho, seja a emancipação do sujeito, restaria ao estudante a responsabilização de seguir esse caminho aprendido. Essa responsabilização do sujeito se espraia ainda para a questão do bem-estar físico e emocional do indivíduo, através do foco nas chamadas competências socioemocionais. Em todas essas questões o Estado aparece totalmente descolado dessas funções, pois, em se tratando de um projeto e um método operado a partir de conhecimentos aprendidos, a solução está criada e deve ser alcançada individualmente.

A aprendizagem é apresentada como a tarefa para a qual a BNCC é instrumento fundamental, como um conjunto orgânico e progressivo de aprendizagens essenciais que todos os alunos devem desenvolver na expectativa de assegurar seus direitos de aprendizagem e desenvolvimento através de competências que assegurem para si esses direitos. Seguir operando com a ideia de aprendizagem é operar na mesma lógica da ideia de ensino, porém abordando a dimensão do estudante. De qualquer maneira, a linguagem da aprendizagem segue a mesma lógica do ensino, em que há um conhecimento objetificado e com objetivo.

Nessa perspectiva da objetificação, queremos retomar a ideia de herança colonial na BNCC. Além do aspecto salvacionista do documento que já mencionamos, também temos a ideia de lucro como parte dessa herança. Existe um envolvimento de instituições privadas nos caminhos apontados pela BNCC, existe uma visão de capitalizar a educação. Ou seja, uma das formas de operação da herança consiste em construir um discurso de resgate, de salvação; mas ter como intenção a busca pelo lucro em uma clara economicização da educação, uma economicização da vida escolar. Em sintonia com o que Brown (2015) chamou de 
economicização da vida e das coisas como efeito da normatividade neoliberal que atravessa discursos e performatividades.

Muito embora o documento performe de forma extremamente sedutora, projetando, entre outras coisas, autonomia e liberdade, quando lemos a norma para quebrar a norma, usando de outras perspectivas como ferramentas de leitura, entendemos que permanência e ausência são duas faces da mesma coisa, ou seja que ao tentarmos misturar educação, aprendizagem e economização, por serem de naturezas que não conversam, cria-se uma colonialidade borrada, um novo que traz algo repetido ou vice versa, levando, assim, à impossibilidade de uma base comum, à derrota da BNCC. Apesar das tentativas de muitos autores, como Biesta (2017), por exemplo, não sabemos se dentro do sistema em que vivemos existem ideias que se encaixem, conversem ou colaborem para a criação de algo que produza o efeito que sonhamos, a escola que sonhamos. Porém, afirmamos com certo conforto que a tentativa de combinação de ideias de educação e aprendizagem proposta no texto da BNCC, além de não se encaixar, se repelem, por esta última não dar conta da performatividade constitutiva da educação.

\section{REFERÊNCIAS BIBLIOGRÁFICAS}

BALL, Stephen. Educação Global S.A.: novas redes políticas e o imaginário neoliberal. Ponta Grossa: Editora UEPG, 2012.

BIESTA, Gert. Para além da aprendizagem: educação democrática por um futuro humano. Belo Horizonte, 2017.

BRASIL. Base nacional comum curricular. Brasília: Ministério da Educação, 2018.

BROWN, Wendy. Undoing demos: neoliberalism's stealth revolution. New York: Zone Books, 2015.

BUTLER, Judith; ATHANASIOU, Athena. Dispossession: The performative in the political. Cambridge: Polity, 2013.

BUTLER, Judith. Corpos em aliança e a política das ruas: notas para uma teoria performativa de assembleia. Rio de Janeiro: Civilização Brasileira, 2018.

DERRIDA, Jacques. Margens da filosofia. Campinas: Papirus Editora, 1991.

DERRIDA, Jacques; ROUDINESCO, Elisabeth. De que amanhã: diálogo. Rio de Janeiro: Jorge Zahar Editora, 2004.

DERRIDA, Jacques. Torres de Babel. Trad. J. Barreto. Belo Horizonte: Editora UFMG, 2009. 
DERRIDA, Jacques. Uma certa possibilidade impossível de dizer o acontecimento. Revista Cerrados, 21(33), 2012.

LOPES, Alice. Normatividade e intervenção política: em defesa de um investimento radical. In: LOPES, A. C.; MENDONÇA, D. A Teoria do Discurso de Ernesto Laclau: ensaios críticos e entrevistas. São Paulo: Annablume, 2015. p. 117-147.

MACEDO, Elizabeth. Base Nacional Curricular Comum: a falsa oposição entre conhecimento para fazer algo e conhecimento em si. Belo Horizonte: Educação em Revista, v.32, n.02, p. 45-67, Abril-Junho 2016.

MACEDO, Elizabeth. A teoria do currículo e o futuro monstro. In: LOPES, Alice Casimiro; SISCAR, Marcos. Pensando política com Derrida: responsabilidade, tradução, porvir. São Paulo: Cortez, 2019. 